ISSN $2230-8695$

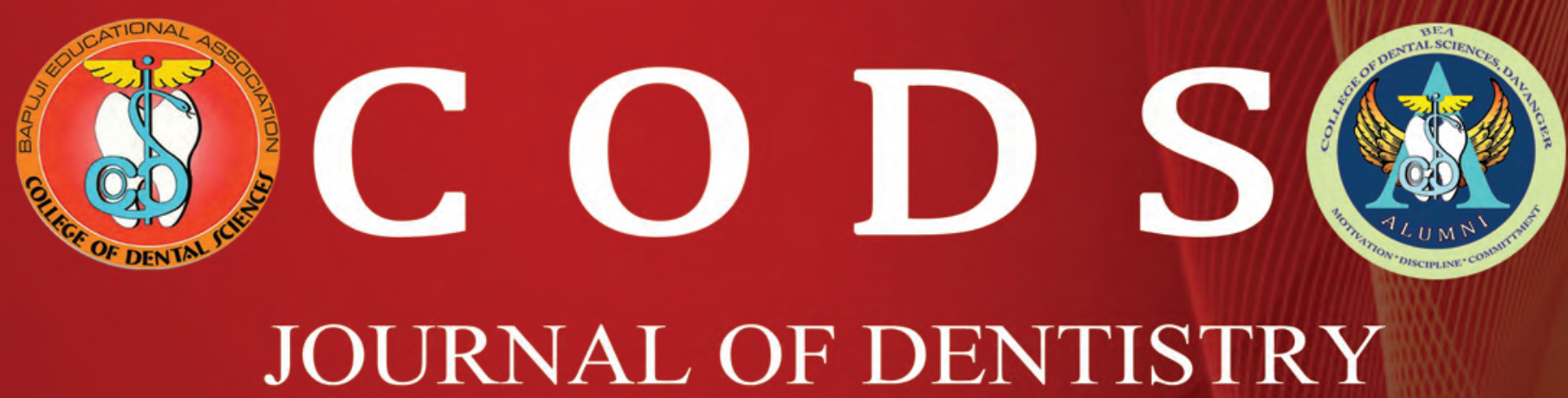

Official Publication of College of Dental Sciences Alumni Association, Davangere.

Volume $6 \cdot$ Issue $1 \bullet 2014$ 


\section{CODS Journal of Dentistry}

Official Publication of College of Dental Sciences Alumni Association, Davanagere

Volume 6, Issue 1, 2014

\section{CONTENTS}

Director's Message

V.V. Subba Reddy

President's Message

Vasundhara Shivanna

Secretary's Message

Praveen S. Basandi

Editorial

Nandini D.B

\section{Original Articles}

Effect of alcohol containing and alcohol free mouth rinses on microhardness of three esthetic restorative materials

Vasundhara Shivanna, Rucha Nilegaonkar

Prevalence and distribution of dental anomalies and fluorosis in a small cohort of

Indian school children and teenagers

Selvamani. M, Praveen S Basandi, Madhushankari G.S

\section{Review Articles}

Paperless dentistry - The future

Mala Ram Manohar, Gajendra Bhansali

Photo activated disinfection in restorative dentistry - A technical review

Deepak B.S, Mallikarjun Goud K, Nishanth P

An overview of occupational hazards in dental practice and preventive measures.

Poorya Naik .D.S, Chetan .S, Gopal Krishna.B.R, Naveen Shamnur

An overview on influences of estrogen and progesterone on periodontium 


\section{CODS Journal of Dentistry}

Official Publication of College of Dental Sciences Alumni Association, Davanagere

\section{Volume 6, Issue 1, 2014}

\section{CONTENTS}

\section{Review Articles}

Dental home - A new approach for child oral health care

Poornima P, Meghna Bajaj, Nagaveni N.B, Roopa K.B, V.V. Subba Reddy

Variants of inferior alveolar nerve block: A review

Anuradha M, Yashavanth Kumar D.S, Harsha .V. Babji, Rahul Seth

\section{Case Reports}

Ellis-van Creveld syndrome affecting siblings: A case report and review

Mamatha G.P, Manisha Jadhav , Rajeshwari G Annigeri, Poornima .P, V.V Subba Reddy

Integrated approach of ceramic and composite veneers in tetracycline

stained teeth: A case report.

Divya K.T, Satish .G

Fibrous dysplasia of right maxilla: A case report and review of literature

Guruprasad .L, Kavita Rao, Uma Devi H.S, Priya N.S

A case report of recurrent herpetic gingivostomatitis; with special reference to the role of cytology in diagnosis

Pramod K Jali, Nandini D.B, Mohan K.P, Madhushankari G.S

Eagle's syndrome with type III segmented styloid process : A case report.

Usha V. A, Mamatha G. P, Maria Priscilla David, 


\title{
Effect of alcohol containing and alcohol free mouth rinses on microhardness of three esthetic restorative materials
}

\author{
Vasundhara Shivanna' Rucha Nilegaonkar ${ }^{2}$ \\ Principal, Professor and Head' ${ }^{1}$, Post Graduate student ${ }^{2}$. \\ Dept of Conservative Dentistry and Endodontics, College of Dental Sciences, Davangere
}

\begin{abstract}
:
Introduction: Daily application of mouth rinses has been recommended for the prevention and control of caries and periodontal disease.
\end{abstract}

Aims \& Objectives: The aim of this study was to evaluate the effect of alcohol-containing and alcohol-free mouth rinses on the microhardness of three restorative materials - resin composite (Filtek Z350XT), light cure glass ionomer cement (Vitremer) and conventional restorative glass ionomer cement (GC Fuji II).

Methods: Twenty samples of each restorative material were fabricated and their microhardness values were checked at $100 \mathrm{~g}$ load and 15 seconds dwell time. Ten samples of each restorative material were stored in alcohol containing mouth rinse (Listerine) and ten samples each were stored in alcohol free mouth rinse (Hiora) for 12 hours. At the end of the test period microhardness was measured with a Vickers microhardness tester.

Results: Alcohol containing mouth rinses reduced the microhardness values of composite and light cure glass ionomer significantly more than alcohol free mouth rinses. Reduction in the microhardness value of conventional restorative glass ionomer cement was similar for both alcohol containing and alcohol free mouth rinses.

Conclusion: Both mouth rinses showed reduction in microhardness values of all three restorative materials, with more reduction caused due to alcohol containing mouth rinses in composite and light cure glass ionomer.

Key words: Resin composite, light cure glass ionomer, glass ionomer restorative cement, mouth rinse, microhardness.

\section{Introduction:}

In recent years, dentists have become increasingly interested in the potential of antimicrobial mouth rinses in the control of plaque in patients. ${ }^{1}$ Given the difficulty of achieving acceptable levels of plaque control with mechanical methods such as brushing and flossing, the use of mouth rinses is appealing to both patients and clinicians. ${ }^{1,2}$

Maintaining dental restorations in the mouth is also important for oral health. Tooth-colored restorations such as composite resins, glass-ionomer cements (GIC) or

\author{
Corresponding Author: \\ Dr. Vasundhara Shivanna \\ Principal \\ Professor and Head \\ Dept. of Conservative Dentistry and Endodontics \\ College of Dental Sciences, Davangere. \\ Ph. No: 9844118814, Phone: 08192-231029. \\ E-mail: vasundharashivanna56@gmail.com
}

fissure sealants require meticulous maintenance. ${ }^{3}$

Mouth rinses contain water, antimicrobial agents, salts, preservatives and in some cases alcohol. Some studies have shown that alcohol in the mouth rinses may soften the resin composite restorative materials and this effect is found to be directly related to the percentage of alcohol., ${ }^{4,5}$

Type of restorative material also influences the degradation of restorative materials. ${ }^{6}$

Currently a wide variety of mouth rinses are available in the market and many of them are not studied for their effect on the restorations. Hence, the aim of the present study was to evaluate and compare the effect of two commercial mouth rinses on the micro hardness of a nanofilled resin composite (Filtek Z350 XT, 3M ESPE, St. Paul, MN, USA), Vitremer (light cure restorative glass ionomer cement) and conventional restorative glass ionomer cement (Fuji II). (Fig 1) 


\section{Materials and method:}

Specimen preparation: 20 specimens of resin composite (FiltekZ350) material with $3 \mathrm{~mm}$ diameter and $3 \mathrm{~mm}$ height were prepared using a plastic mold. The mold was placed on a glass slide and filled with resin composite (Fig 2) to a slight excess using composite filling instrument, covered with another glass slide was placed on top and gently pressed for 30sec to extrude excess material to obtain a smooth surface (Fig 3). Each specimen was cured for 40sec from the top and another 40sec from the bottom using LED light cure unit (3M ESPE Elipar S10).

20 specimens of light cure glass ionomer (Vitremer) were be prepared by manipulating it according to manufacturer's instructions. After manipulation, the specimens were prepared in a manner similar to the composite specimens by filling them into plastic molds and light curing them.

20 specimens of conventional GIC (GC Fuji II) were also prepared. After manipulating the material according to manufacturer's instructions, it was placed into plastic moulds of 3mm diameter and 3mm height. The mould was placed on a glass slide and covered with another glass slide over it. The glass slides were gently pressed and held in this position till the material set by chemical reaction.

The specimens were randomly allocated into 2 major groups by simple random sampling according to the mouth rinses. Each group was further divided into 3 subgroups based on the restorative material. Each subgroup had 10 specimens of the respective restorative material.

I. Group I: Listerine (alcohol-based; 21.6\% alcohol)

a. FiltexZ350 $(\mathrm{n}=10)$

b. Vitremer $(\mathrm{n}=10)$

c. GC Fuji II ( $\mathrm{n}=10)$

II. Group II: Hiora (alcohol free)

a. FiltexZ350 $(\mathrm{n}=10)$

b. Vitremer $(\mathrm{n}=10)$

c. GC Fuji II $(\mathrm{n}=10)$

The baseline micro hardness values of the specimens were recorded prior to immersion in the mouth rinses. Micro hardness was measured using Vicker's micro hardness tester (Reichert Austria Make. Sr. No. 363798). A load of $100 \mathrm{~g}$ was applied on the test specimens with a dwell time of 15sec. (Fig. 4)

The specimens were then immersed in $20 \mathrm{ml}$ of respective mouth rinses and kept for $12 \mathrm{hrs}$.

Then specimens were then removed from the mouth rinses and dried. Micro hardness values were then checked for each specimen using the same micro hardness tester and same load and dwell time as previously mentioned for pre-immersion test.

\section{Statistical analysis:}

Pre-immersion and post-immersion values were compared using the Paired $\mathrm{T}$ Test for both alcohol free and alcohol containing mouth rinses.

\section{Results:}

Significant reduction in the micro hardness was observed in Group I as well as group II after immersion in the mouth rinse compared to baseline values. $(\mathrm{P}<0.05)$

More significant reduction was seen in the microhardness of Filtek Z350 XT after immersion in the alcohol containing mouth rinse $(\mathrm{P}=0.03)$ as compared to alcohol free mouth rinse $(\mathrm{P}=0.05)$. Similarly, for Vitremer, more significant reduction in microhardness was seen in alcohol containing group $(\mathrm{P}=0.005)$ as compared to alcohol free group $(\mathrm{P}=0.01)$. For restorative GIC (Fuji II), similar reduction in microhardness values was seen in both alcohol containing and alcohol free groups $(\mathrm{P}=0.009)$.

Table 1: The pre-immersion and post-immersion values

\begin{tabular}{|c|c|c|c|}
\hline \multirow{2}{*}{ Res torative Materials } & \multirow{2}{*}{$\begin{array}{l}\text { Pre immersion } \\
\text { (Vickers } \\
\text { Microhardness } \\
\text { Number) }\end{array}$} & \multicolumn{2}{|c|}{$\begin{array}{c}\text { Post immersion (Vickers Microhardness } \\
\text { Number) }\end{array}$} \\
\hline & & $\begin{array}{l}\text { Alcohol Containing } \\
\text { (Lis te rine) group I }\end{array}$ & $\begin{array}{c}\text { Alcohol Free (Hiora) } \\
\text { group II }\end{array}$ \\
\hline a. Filtek Z350 XT & 70.12 & 60.21 & 67.54 \\
\hline b. Vitremer & 52.97 & 41.19 & 50.17 \\
\hline c. Fuji II restorative & 46.22 & 43.36 & 43.70 \\
\hline
\end{tabular}

\section{Discussion:}

During the last few years, caries prevalence has declined sharply in populations. This decrease is generally attributed to improvements in oral hygiene and preventive dentistry. Consequently, the concepts of traditional dentistry are being questioned progressively and there is new impetus for more conservative adhesive techniques. Black's cavities favoring the use of amalgam have at least partially been replaced by minimal cavities determined by the extent of caries. Along with this development, a change in the selection of restorative materials is obvious. ${ }^{7}$

The present in-vitro study was designed to comparatively evaluate the effect of mouth rinses on the micro hardness of a nanofilled resin composite Filtek Z350 XT, Vitremer and Fuji II restorative glass ionomer cement. Listerine is an alcohol-based mouth rinse and Hiora is an alcohol-free mouth rinse.

Hardness is considered as the test parameter, as it is an important property for the restorative materials to have long-term durability in the oral cavity. ${ }^{8}$ 
Hardness has also been used to predict the wear resistance of a material and its ability to abrade or be abraded by opposing dental structures and materials. ${ }^{9}$ Decrease in the hardness of a material may result in premature failure of a restoration requiring its replacement.

In the present study, both the mouth rinses irrespective of the presence or absence of alcohol resulted in significant reduction in the micro hardness of the tested resin composite compared to base line value. This may be because of the acidic $\mathrm{pH}$ of the mouth rinses which would have caused acid erosion of the resin composite by acid etching and leaching the principle matrix forming cations. This is in accordance with the observations by Dieb et al in 2007, who reported that mouth rinses with low $\mathrm{pH}$ were detrimental to the hardness of resin composites $^{10}$. The low $\mathrm{pH}$ of mouth rinses may have acted in the polymeric matrix of the nanofilled resin composite used in the study, through catalysis of ester groups from dimethacrylate monomers present in the composition (Bis GMA, Bis EMA, UDMA and TEG DMA). The hydrolysis of these ester groups may have formed alcohol and carboxylic acid molecules that may have accelerated the degradation of the resin composite. ${ }^{11}$

Significant reduction of microhardness was observed for light cure glass ionomer cement (Vitremer) as well, which was more for the alcohol containing mouth rinse group. Similar results were seen in a study performed by Kao EC, who stated that the softening effect of alcohol in the mouth rinses on the light cure glass ionomer cement may be due to susceptibility of Bis GMA and UDMA based polymers present in them and irreversible leaching of the components. ${ }^{12,13 .}$

A reduction in microhardness occurred in case of conventional glass ionomer cement as well, which was almost equal for both the groups. This result is in accordance with a study conducted by Geurtsen in which it was concluded that the reduction in microhardness value could be because of the water component of the mouth rinses. ${ }^{14}$ It has been observed that the basic constituents of GI cements, that are the polycarboxylic acids and ion leachable glasses, bind water molecules. Water causes eroding of the surface of the cement leading to its hydrolysis and dissolution of some of its components resulting in decreased microhardness.

Clinically, the effects of mouth rinses on restorative materials may be modified by many factors which may not be replicated in an in vitro setting. Saliva may dilute or buffer the mouth rinse, thus reducing the softening effect and a coating of salivary pellicle might have a protective effect. Studies are therefore necessary to determine the effects of these mouth rinses in vivo.

\section{Conclusion:}

Within the limitations of this study, it can be concluded that

- All the mouth rinses used in the study irrespective of the presence or absence of alcohol reduced the micro hardness of resin composite, light cure glass ionomer and conventional restorative glass ionomer cement.

- Alcohol containing mouth rinse (Listerine) brought about significantly more reduction in microhardness of composite and light cure glass ionomer cement.

In conclusion, mouth rinses can affect the hardness of restorative materials. Alcohol content clearly is not the only factor that has a softening effect on the materials.

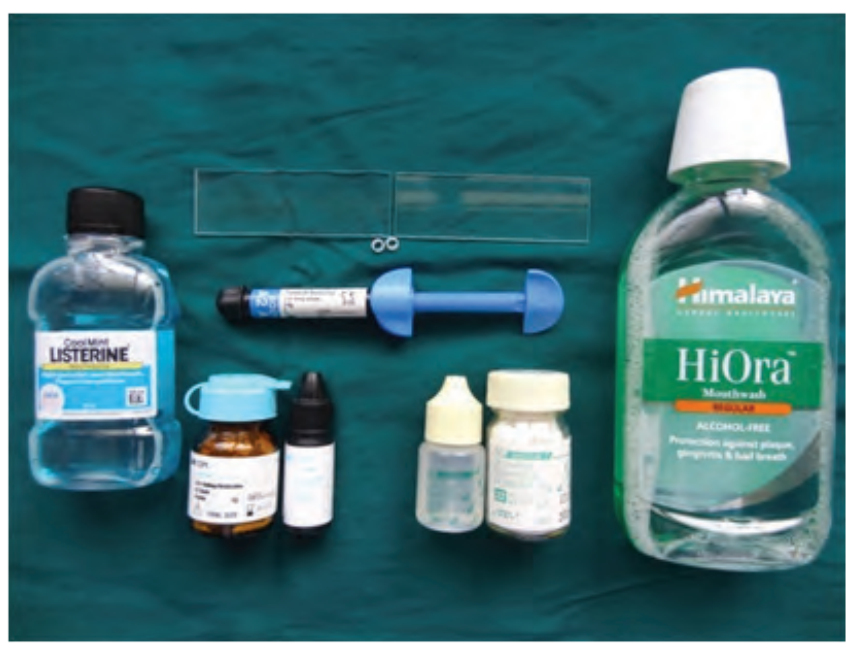

Fig 1: Materials used: Filtek Z350 XT, Vitremer, GC Fuji II glass ionomer

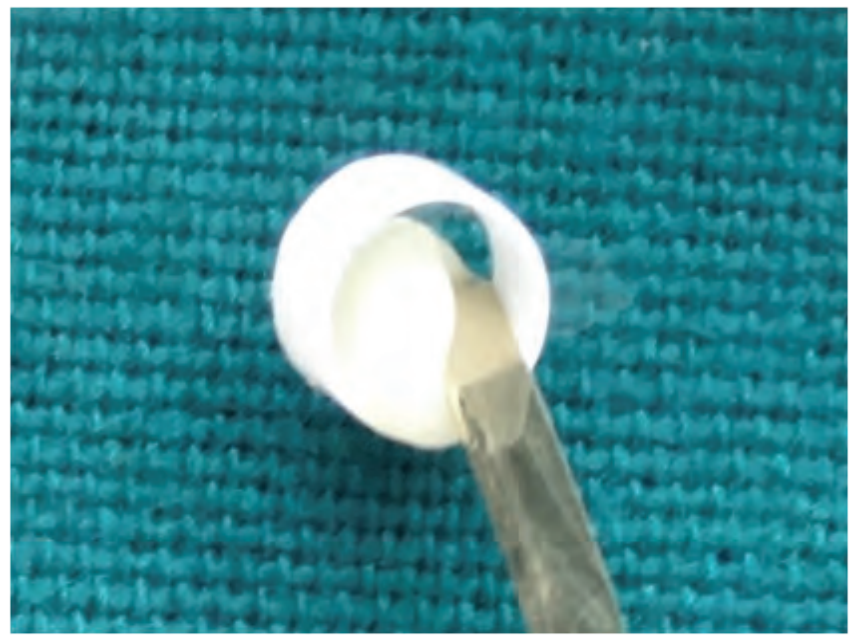

Fig 2: Packing composite into plastic mold 


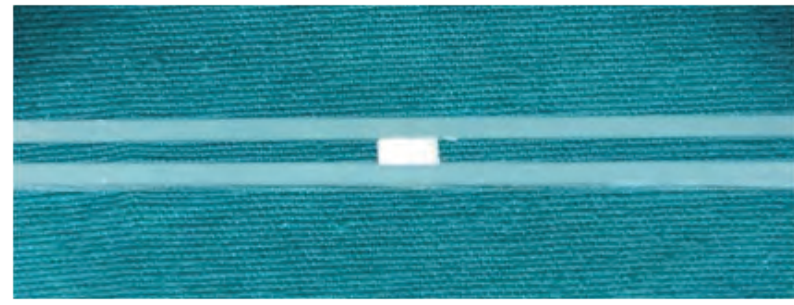

Fig 3: Mold between two glass slides to extrude excess material

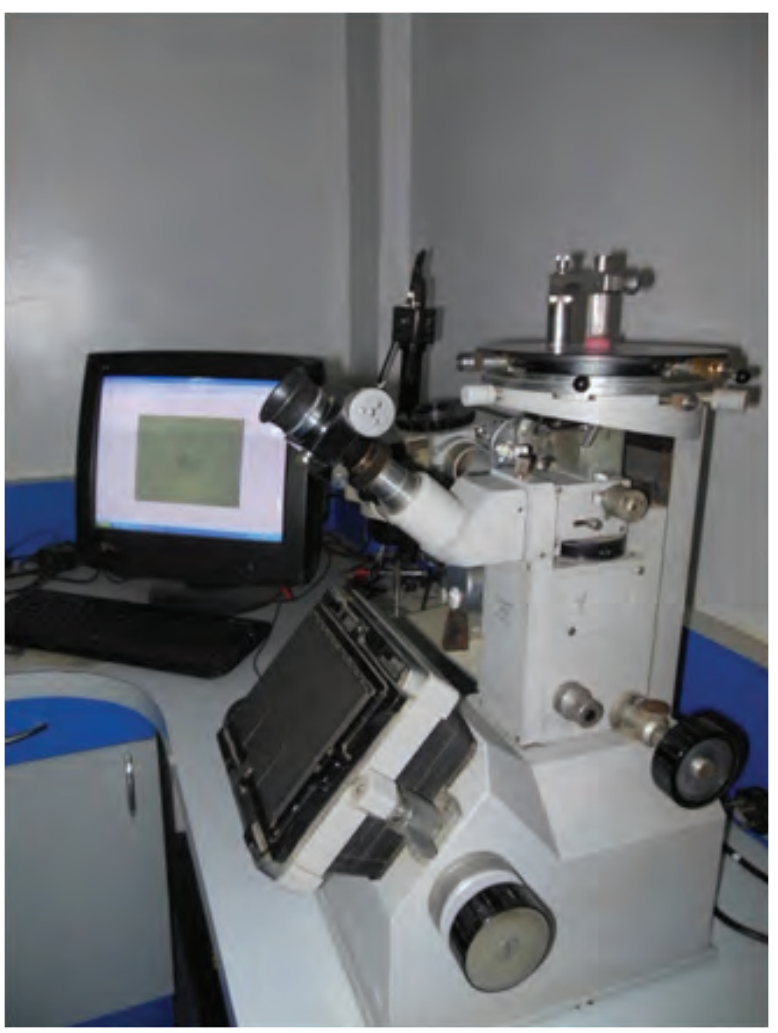

Fig 4: Microhardness tester

(Reichert Austria Make. Sr. No. 363798)

\section{References:}

1.Devore LR. Antimicrobial mouth rinses: impact on dental hygiene. J Am Dent Assoc.1994;125:23.

2.Fischman SL. A clinician's perspective on antimicrobial mouthrinses. J Am Dent Assoc. 1994;125:20.

3.Goldstein RE, Garber DA, Schwartz CG, Goldstein CE. Patient maintenance of esthetic restorations. J Am Dent Assoc. 1993;123:61.

4.Asmussen E. Softening of BIS GMA based polymers by ethanol and by organic acids of plaque. Scand $\mathrm{J}$ Dent Res. 1984;92:257-61.
5. Penugonda B, Settembrini L, Scherer W, Hittel E, Strassler H. Alcohol containing mouth washes: Effects on composite hardness. J Clin Dent. 1994;5:60-2.

6. Gurgan S, Oner A, Koprulu H. In vitro effects of alcohol containing and alcohol free mouth rinses on micro hardness of some restorative materials. J Oral Rehab.1997;24:244-6.

7. Widstrom E, Forrs H. Selection of restorative materials in dental treatment of children and adults in public and private dental care in Finland. Swed Dent J. 1994;18:1.

8. Okada K, Tosaki S, Hirota K, Hume WR. Surface hardness change of restorative filling materials in saliva. Dent Mater. 2001;17:34-9.

9. Anusavice KL. Mechanical properties of dental materials. 10th ed. Philadelphia: WB Saunder's Co; 1996. p. 69.

10.Diab M, Zaazou MH, Mubarak EH, Olaa MI Fahmy. Effect of five commercial mouth rinses on the micro hardness and color stability of two resin composite restorative materials. Aust J Basic Appl Sci. 2007;1:667-4.

11. Gopferich A. Mechanisms of polymer degradation and erosion. Biomaterials.1996;17:103-14.

12. Kao EC. Influence of food stimulating solvents on resin composites and glass ionomer restorative cement. Dent Mater. 1989;5:201-8.

13. Lee SY, Geener EH, Menis DL. Detection of leached moieties from dental composites in fluid simulating food and saliva. Dent Mater. 2000;16:33-40.

14. Geurtsen W, Leyhausen G, Garcia-Godoy F. Effect of storage media on the fluoride release and surface microhardness of four polyacid-modified composite resins (compomers). Dent Mater J 1999;15:196.

How to cite this article:

Vasundhara S, Rucha N. Effect of alcohol containing and alcohol free mouth rinses on microhardness of three esthetic restorative materials. CODS J Dent 2014;6;5-8

Source of support: Nil. Conflict of interest: None Declared. 